\title{
VPAC1 Receptors for Imaging Breast Cancer: A Feasibility Study
}

\author{
Mathew L. Thakur ${ }^{1,2}$, Kaijun Zhang ${ }^{1}$, Adam Berger ${ }^{3}$, Barbara Cavanaugh ${ }^{1}$, Sung Kim ${ }^{1}$, Chaitra Channappa ${ }^{1}$, \\ Andrea J. Frangos ${ }^{1}$, Eric Wickstrom ${ }^{2,4}$, and Charles M. Intenzo ${ }^{1}$ \\ ${ }^{I}$ Department of Radiology, Thomas Jefferson University, Philadelphia, Pennsylvania; ${ }^{2}$ Kimmel Cancer Center, Thomas Jefferson \\ University, Philadelphia, Pennsylvania; ${ }^{3}$ Department of Surgery, Thomas Jefferson University, Philadelphia, Pennsylvania; and \\ ${ }^{4}$ Department of Biochemistry and Molecular Biology, Thomas Jefferson University, Philadelphia, Pennsylvania
}

\begin{abstract}
VPAC1 encodes G-protein-coupled receptors expressed on all breast cancer $(\mathrm{BC})$ cells at the onset of the disease, but not on benign lesions. Our extensive preclinical studies have shown that ${ }^{64} \mathrm{Cu}-\mathrm{TP} 3805$ has a high affinity for VPAC1, is stable in vivo, and has the ability to distinguish spontaneously grown malignant $\mathrm{BC}$ masses from benign lesions. Our long-term goal is to develop ${ }^{64} \mathrm{Cu}$-TP3805 as an agent to perform in vivo histology, to distinguish malignant lesions from benign masses noninvasively and thereby avoid patient morbidity and the excess economic costs of benign biopsies. Methods: ${ }^{18} \mathrm{~F}-\mathrm{FDG}$ obtained commercially served as a control. ${ }^{64} \mathrm{Cu}$-TP3805 was prepared using a sterile kit containing $20 \mu \mathrm{g}$ of TP3805. Radiochemical purity and sterility were examined. Nineteen consenting women with histologically proven $\mathrm{BC}$ were given $370 \mathrm{MBq}$ of ${ }^{18} \mathrm{~F}-\mathrm{FDG}$. One hour later, 6 of these patients were imaged with $\mathrm{PET} / \mathrm{CT}$ and 13 with positron emission mammography (PEM). Two to $7 \mathrm{~d}$ later, $6 \mathrm{PET} / \mathrm{CT}$ patients received $111 \mathrm{MBq}$ $( \pm 10 \%)(n=2), 127 \mathrm{MBq}( \pm 10 \%)(n=2)$, or $148 \mathrm{MBq}( \pm 10 \%)$ $(n=2)$ of ${ }^{64} \mathrm{Cu}$-TP3805 and were imaged 2 and $4 \mathrm{~h}$ later. Thirteen PEM patients received $148 \mathrm{MBq}( \pm 10 \%)$ of ${ }^{64} \mathrm{Cu}$-TP3805 and were imaged $15 \mathrm{~min}, 1 \mathrm{~h}, 2 \mathrm{~h}$, and $4 \mathrm{~h}$ later. Standardized uptake value (SUV) was calculated for PET/CT patients, and PUV/BGV (PEM uptake value/background value) was calculated for PEM patients. Tumor volume was also calculated. Results: The radiochemical purity of ${ }^{64} \mathrm{Cu}$-TP3805 was $97 \% \pm 2 \%$, and specific activity was $44.4 \mathrm{GBq}$ $(1.2 \mathrm{Ci}) / \mu \mathrm{mol}$. In 19 patients, a total of 24 lesions were imaged (15 invasive ductal carcinoma, 1 high-grade mammary carcinoma, 3 lobular carcinoma, 1 invasive papilloma, and 4 sentinel lymph nodes). All lesions were unequivocally detected by ${ }^{64} \mathrm{Cu}$-TP3805 and by ${ }^{18} \mathrm{~F}-\mathrm{FDG}$. The average tumor volume as determined by PET/CT with ${ }^{64} \mathrm{Cu}$-TP3805 was $90.6 \% \pm 16.1 \%$ of that with ${ }^{18} \mathrm{~F}$ FDG PET/CT, and the average SUV was $92 \% \pm 26.4 \%$ of that with ${ }^{18} \mathrm{~F}-\mathrm{FDG}$. For PEM, the tumor volume with ${ }^{64} \mathrm{Cu}$-TP3805 was $113 \% \pm 37 \%$ of that with ${ }^{18} \mathrm{~F}-\mathrm{FDG}$ and the PUV/BGV ratio was $97.7 \% \pm 24.5 \%$ of that with ${ }^{18} \mathrm{~F}-\mathrm{FDG}$. Conclusion: ${ }^{64} \mathrm{Cu}-\mathrm{TP} 3805$ is worthy of further investigation in patients requiring biopsy of suggestive imaging findings, to further evaluate its ability to distinguish malignant lesions from benign masses noninvasively.
\end{abstract}

\footnotetext{
Received Oct. 1, 2012; revision accepted Jan. 22, 2013.

For correspondence or reprints contact: Mathew L. Thakur, Thomas Jefferson University, 1020 Locust St., Ste. 359 JAH, Philadelphia, PA 19107. E-mail: mathew.thakur@jefferson.edu

Published online May 7, 2013.

COPYRIGHT (C) 2013 by the Society of Nuclear Medicine and Molecular Imaging, Inc.
}

Key Words: targeting VPAC1; ${ }^{64} \mathrm{Cu}-\mathrm{TP} 3805$ for PEM; ${ }^{64} \mathrm{Cu}-\mathrm{TP} 3805$ for PET; in vivo histology

J Nucl Med 2013; 54:1019-1025

DOI: 10.2967/jnumed.112.114876

$\mathbf{O}$ the approximately 1.6 million breast biopsies that were performed in the United States in 2011, about 288,130 breast cancers (BCs) were diagnosed (230,480 invasive and 57,650 in situ) $(1,2)$, but over 1.3 million of these biopsies resulted in a benign diagnosis. These unnecessary biopsies create significant patient morbidity and potentially unnecessary health care costs. To detect BC, digital mammography, MRI, CT, sonography,

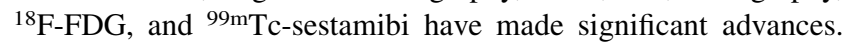
However, all of these modalities have limited specificity, and all continue to produce many false-positive and false-negative results (3-12). At an average cost of \$5,000-\$6,000 for each biopsy, unnecessary benign biopsies represent a serious health care burden. There is a compelling need for an innovative approach that would decrease the number of unnecessary benign biopsies while still detecting the malignancies.

Recent approaches to drug discovery focus on understanding the genesis of diseases and the biomedical pathways that control them at a molecular level. Previous studies have demonstrated that VPAC1 receptors (combined for vasoactive intestinal and pituitary adenylate cyclase activating peptide [PACAP]) are overexpressed in high density on $\mathrm{BC}$ (13). VPAC1 receptors encode a $\mathrm{G}$ protein involved in cell proliferation, cell differentiation, and survival of BC cells. On stroma, normal cells, and benign masses, only a few VPAC1 receptors are expressed (13-18).

We therefore hypothesized that a radiolabeled biomolecule with a high affinity for VPAC1 receptors would not only image BC early but also distinguish malignant lesions from benign masses. To validate this hypothesis on a molecular level, a large body of preclinical data was generated (19-27). On the basis of their high affinity for VPAC1 receptors, we chose 4 peptide constructs, modified them for radiolabeling with ${ }^{99 \mathrm{~m}} \mathrm{Tc}$ (half-life $\left[\mathrm{t}_{1 / 2}\right], 6 \mathrm{~h}$; $\gamma$-energy, $140 \mathrm{keV}$ ), and evaluated them for receptor affinity (dissociation constant), receptor specificity, in vivo stability, and tissue distribution (20-27). Impetus generated from these results prompted us to label the 4 molecules with $\beta+(19 \%, 656 \mathrm{keV})$ emitting ${ }^{64} \mathrm{Cu}\left(\mathrm{t}_{1 / 2}, 12.8 \mathrm{~h}\right)$ for PET. We used $\mathrm{N}_{2} \mathrm{~S}_{2}$ chelating agent, determined dissociation constants, performed tissue distribution studies 
in athymic nude mice bearing T47D human BC, performed receptor blocking studies, determined receptor affinity, and examined their stability in vivo (23-27).

After a critical evaluation of these data, we chose a PACAP analog, ${ }^{64} \mathrm{Cu}-\mathrm{TP} 3805$, for further evaluation. ${ }^{64} \mathrm{Cu}-\mathrm{TP} 3805$ not only imaged all xenografted human $\mathrm{BC}$ in athymic nude mice (tumor uptake, $6.35 \% \pm 1.28 \%$ injected dose/g at $24 \mathrm{~h}$ after injection) but also localized all $(n=8)$ spontaneously grown BC (5 visible, 1 invisible, and 2 metastatic) lesions in transgenic MMTVneu mice $(n=9)$ (26). Furthermore, the ${ }^{64} \mathrm{Cu}-\mathrm{TP} 3805$ PET images were normal for 2 lesions that had negligible expression of VPAC1 receptors. These were benign histologically as examined by an independent senior pathologist. These 2 benign lesions displayed prominent ${ }^{18} \mathrm{~F}$-FDG images. Among the 8 malignant lesions, only 4 were imaged by ${ }^{18} \mathrm{~F}-\mathrm{FDG}$. All malignant lesions $(n=8)$ were confirmed by histology and expressed VPAC1 receptors as determined by RT-PCR (26). The 2 histologically determined benign lesions had negligible expression of VPAC1 receptors. Spontaneous growth of BC in MMTVneu mice resembled the pathophysiology of human BC. Further evidence of the receptor specificity of ${ }^{64} \mathrm{Cu}-\mathrm{TP} 3805$ was obtained by digital autoradiography of human $\mathrm{BC}$ specimens, in which ${ }^{64} \mathrm{Cu}-\mathrm{TP} 3805$ had nearly 6 times greater uptake of radioactivity $(n=5)$ than that of benign stroma (24). These highly encouraging data, particularly the ability of the probe to image only malignant lesions with high specificity, prompted us to undertake this study in humans.

In this article, we will describe the feasibility of imaging $\mathrm{BC}$ in humans with ${ }^{64} \mathrm{Cu}-\mathrm{TP} 3805$ using PET and positron emission mammography (PEM) scanners.

\section{MATERIALS AND METHODS}

\section{TP3805 Synthesis and Kit Preparation}

Briefly, the PACAP analog with a C-terminal diaminodithiol $\left(\mathrm{N}_{2} \mathrm{~S}_{2}\right)$ chelator was synthesized (25-29) on a Wang resin using an ABI 341A peptide synthesizer (Applied Biosystems). Fmoc-Lys (ivDde) was first introduced at the $\mathrm{C}$ terminus of the peptide, followed by 4-aminobutyric acid (y-Aba). The 27-amino-acid PACAP sequence was then assembled by standard Fmoc coupling, with the final histidyl residue being a t-Boc-protected His(Trt) derivative. The capping t-Boc function was necessary to ensure that the $\mathrm{N}$-terminal amino group remained protected during subsequent deprotection and coupling cycles performed at the y-amino group of the $\mathrm{C}$-terminal lysine. The ivDde group at the C-terminal lysine was then selectively removed with $2 \%$ hydrazine, followed by successive additions of di-Fmoc-Ldiaminopropionic acid and $S$-benzoylthioglycolic acid. The resulting protected diaminedithiol (NS-benzoyl $)_{2}$-containing PACAP peptide was cleaved from the resin using trifluoroacetic acid:water:phenol: thioanisole:ethanedithiol (82.5:5:5:5:2.5) and precipitated with diethyl ether.

The crude peptide was purified to homogeneity by reverse-phase high-pressure liquid chromatography (Waters) on a Vydac C4 column $(5 \mu \mathrm{m}, 10 \times 250 \mathrm{~mm})$. The mass of the analog-chelator construct was confirmed by electrospray mass spectrometry. Following the general synthetic scheme, TP3805 was prepared, purified, and characterized by American Peptide Co.

Kits were prepared aseptically in a laminar flow hood. All reagents were sterilized, including 10-mL glass vials, rubber caps, and aluminum sealing caps. All reagents were of analytic grade, were obtained from Fisher Scientific, Inc., and were used without further purification. The reagents added were $100 \mu \mathrm{g}$ of $\mathrm{SnCl}_{2} \cdot 2 \mathrm{H}_{2} \mathrm{O}(10 \mathrm{mg} / \mathrm{mL}, 0.05 \mathrm{M}$ $\mathrm{HCl})$ containing $100 \mu \mathrm{g}$ of glucoheptonate $\left(50 \mathrm{mg} / \mathrm{mL}, \mathrm{H}_{2} \mathrm{O}\right), 20 \mu \mathrm{g}$ of TP3805 (10 mg/mL, and 0.1 M Na-acetate, pH 5), and $200 \mu \mathrm{L}$ of $0.2 \mathrm{M}$ glycine buffer, $\mathrm{pH}$ 9. The mixture was quickly frozen by placing the vials in an acetone and dry ice bath. The vials were then lyophilized for $4 \mathrm{~h}$ (SF50; Genevac), sterile $\mathrm{N}_{2}$ gas was introduced in the chamber, and the vials were sealed, labeled, and stored at $4{ }^{\circ} \mathrm{C}$ until use. The stability of the kits was checked by high-pressure liquid chromatography and for their ability to be labeled with ${ }^{64} \mathrm{Cu}$.

\section{Preparation of ${ }^{64} \mathrm{Cu}-\mathrm{TP} 3805$}

On the day of preparation, a kit vial was removed and brought to room temperature. The required quantity of ${ }^{64} \mathrm{Cu}$ solution (Washington University) was added to the vial (usually $222 \mathrm{MBq}$ in $<20 \mu \mathrm{L}$ of $0.1 \mathrm{M} \mathrm{HCl}$ ), followed by $200 \mu \mathrm{L}$ of sterile water. The vial was incubated at $50^{\circ} \mathrm{C}$ for $90 \mathrm{~min}$. The solution was then diluted by the addition of $2 \mathrm{~mL}$ of sterile $0.9 \% \mathrm{NaCl}$.

The reaction mixture was analyzed by high-pressure liquid chromatography, with a reverse-phase Microbond column (Varian, Inc.) eluted with a linear 28-min gradient from $10 \%$ to $90 \%$ acetonitrile in aqueous $0.1 \%$ trifluoroacetic acid. (Labeling efficiency of $\geq 95 \%$ was considered the criterion for kit stability.) This procedure rendered a ${ }^{64} \mathrm{Cu}-\mathrm{TP} 3805$ specific activity of $44.4 \mathrm{GBq}(1.2 \mathrm{Ci} / \mu \mathrm{mol})$.

\section{Sterility Test}

A required activity for patient injection was drawn into a sterile syringe and measured in a calibrated ionization chamber (CRC-15R; Capintec). Approximately $100 \mu \mathrm{L}$ of the solution were added to 10 $\mathrm{mL}$ of tryptic soy broth and kept for $7 \mathrm{~d}$ in a humidified $5 \% \mathrm{CO}_{2}$ incubator at $37^{\circ} \mathrm{C}$. The test tube was observed daily for $7 \mathrm{~d}$ to detect turbidity or microbial growth.

\section{Patient Inclusion}

Exploratory investigational new drug (eIND) number 101550 was assigned by the Food and Drug Administration. Approval was also obtained from the Institutional Review Board, Clinical Cancer Research Review Committee, and Radioactive Drug Research Committee. Nonpregnant women at least 18 y old and with newly diagnosed, histologically proven BC were enrolled. Image-guided percutaneous biopsy was performed 2-6 wk before this imaging procedure. All patients signed the Institutional Review Board-approved informed consent form. For this feasibility study, a Thomas Jefferson University biostatistician determined that 6 patients should be studied with PET and 13 with PEM. This determination was based on the assumption that ${ }^{64} \mathrm{Cu}-\mathrm{TP} 3805$ will detect $80 \%$ of the lesions and that there will be $87 \%$ power to conclude that this agent is promising.

\section{PET/CT Imaging}

Each patient fasted for $6 \mathrm{~h}$ before ${ }^{18} \mathrm{~F}-\mathrm{FDG}$ injection. Before ${ }^{18} \mathrm{~F}-$ FDG injection, blood glucose was monitored. All enrolled patients had glycemia levels well below $200 \mathrm{mg} / \mathrm{dL}$. Each patient then received $370 \mathrm{MBq}(10 \mathrm{mCi})$ of ${ }^{18} \mathrm{~F}$-FDG through an indwelling intravenous catheter and $1 \mathrm{~h}$ later underwent a PET/CT or PEM scan. PET/CT images were obtained with the patient supine and with a 2-min bed time using a Biograph-6 PET/CT scanner (Siemens, Inc.).

For ${ }^{64} \mathrm{Cu}-\mathrm{TP} 3805$ imaging, patients neither fasted nor had their blood glycemic levels determined. ${ }^{64} \mathrm{Cu}-\mathrm{TP} 3805$ was injected intravenously 2-30 d after the ${ }^{18}$ F-FDG scan. As suggested by the Food and Drug Administration, $111 \mathrm{MBq}(3 \mathrm{mCi})( \pm 10 \%)$ were given to 2 patients, $127.5 \mathrm{MBq}(3.5 \mathrm{mCi})( \pm 10 \%)$ to 2 patients, and $148 \mathrm{MBq}$ (4 mCi) $( \pm 10 \%)$ to the 2 remaining patients. For ${ }^{64} \mathrm{Cu}-\mathrm{TP} 3805$ wholebody scans, the bed time was $4 \mathrm{~min}$ and images were obtained at 2 and $4 \mathrm{~h}$ after injection. A 4-min bed time for ${ }^{64} \mathrm{Cu}-\mathrm{TP} 3805 \mathrm{PET} / \mathrm{CT}$ imaging allowed compensating for the low $\beta+$ yield $(19 \%)$ of ${ }^{64} \mathrm{Cu}$. A 2- and 4-h whole-body imaging time was chosen to determine the optimal imaging time. 


\section{PEM Imaging}

For PEM imaging (Solo I; Naviscan), each patient received $148 \mathrm{MBq}(4 \mathrm{mCi})( \pm 10 \%)$ of ${ }^{64} \mathrm{Cu}-\mathrm{TP} 3805$ or $370 \pm 29.6 \mathrm{MBq}$ $(10 \pm 0.8 \mathrm{mCi})$ of ${ }^{18} \mathrm{~F}-\mathrm{FDG}$ through an indwelling intravenous catheter. Images were obtained for both breasts in mediolateral oblique and craniocaudal positions for $10 \mathrm{~min}$ per view. Data were collected at $15 \mathrm{~min}, 1 \mathrm{~h}, 2-3 \mathrm{~h}$, and $5 \mathrm{~h}$ after injection to determine the optimal imaging time.

Vital signs for each PET/CT and PEM patient were monitored before injection and then for every $30 \mathrm{~min}$ until $4 \mathrm{~h}$ after injection. At the end of the injection, the syringe and the tubing were flushed with $5 \mathrm{~mL}$ of $0.9 \% \mathrm{NaCl}$ and the radioactivity remaining was measured. During the course of the PEM study, patients were allowed to drink or eat if they wished.

\section{Image Analysis}

All images were read by 2 board-certified nuclear medicine physicians and a board-certified breast imaging physician. Image analysis was performed by a nuclear medicine fellow. For 6 patients with PET/CT images for both agents, standardized (maximal) uptake value (SUV) was calculated for the primary tumor site and metastatic lymph nodes and was compared for the respective radiotracers. Metabolic tumor volume was calculated using 50\% isocontour geometry for comparison, as it is relatively a better parameter than SUV and may lead to a detection limit, if any, by the new agent.

For the 13 patients with PEM scans for both agents, PEM uptake values (PUVs) and tumor volumes were calculated for comparison. PEM (maximal) uptake value/background value (PUV/BGV) and mean SUV/PUV ratios were also calculated with each radiotracer and compared for evaluation.

\section{RESULTS}

\section{${ }^{64} \mathrm{Cu}-\mathrm{TP} 3805$ Radiochemical Purity and Sterility}

For all ${ }^{64} \mathrm{Cu}-\mathrm{TP} 3805$ preparations, the radiochemical purity as determined by high-pressure liquid chromatography averaged $97 \% \pm 2 \%$. The specific activity of the preparations averaged 44.4 GBq $(1.2 \mathrm{Ci}) / \mu \mathrm{mol}$. All preparations were sterile. The total radioactivity remaining in the syringe and the intravenous line was less than $5.5 \mathrm{MBq}(150 \mu \mathrm{Ci})$.

\section{Patient Population}

Patients were recruited in consecutive order as they consented. None of the patients had received any form of therapy for BC. The average age of the $6 \mathrm{PET} / \mathrm{CT}$ patients was $48.7 \pm 6.2 \mathrm{y}$ (range, 42-59 y). The average age of the 13 PEM patients was $54 \pm 14.2$ y (range, 26-80 y). Of the total of 19 patients, 2 patients experienced a flushing sensation that resolved within minutes without any medication. The demographic patient data are given in Table 1 together with critical results.

\section{Image Analysis}

In the whole-body PET/CT group, all 6 patients had histologically proven invasive ductal carcinoma. Five of these were estrogen receptor (ER)-positive, 1 ER-negative, 5 progesterone receptor (PR)-positive, $1 \mathrm{PR}$-negative, 2 human epidermal growth factor receptor $2\left(\mathrm{HER}_{2}\right)$-positive, and $4 \mathrm{HER}_{2}$-negative. The quality for each image, irrespective of the quantity of ${ }^{64} \mathrm{Cu}$ TP3805 the patients received, was excellent. Among these patients, there were a total of 10 lesions detected both by ${ }^{18} \mathrm{~F}-$ FDG PET/CT and by ${ }^{64} \mathrm{Cu}-\mathrm{TP} 3805 \mathrm{PET} / \mathrm{CT}$. Of these, 6 were primary (1 lesion in each patient) and 4 involved lymph nodes ( 2 in 1 patient [Fig. 1] and 1 each in the other 2 patients).
In the PEM group of 13 patients, 9 had histologically proven invasive ductal carcinoma, 2 had invasive lobular carcinoma, 1 had invasive papillary carcinoma, and 1 had high-grade mammary carcinoma. Of these, all 13 were ER-positive and none were ER-negative. Eight patients had PR-positive lesions and 5 had PR-negative. Of these, 2 were $\mathrm{HER}_{2}$-positive and 7 were $\mathrm{HER}_{2}$ negative, and for 4 , the $\mathrm{HER}_{2}$ status was indeterminate. One patient with invasive lobular carcinoma had 2 distinct lesions. These demographic data are given in Table 1.

The primary tumor volume in these 6 patents as determined by ${ }^{18}$ F-FDG PET/CT scans ranged from 113 to $6,084 \mathrm{~mm}^{3}$. The corresponding tumor volume as determined by the ${ }^{64} \mathrm{Cu}-$ TP3805 PET/CT scans ranged from 113 to $5,323 \mathrm{~mm}^{3}$. The ${ }^{64} \mathrm{Cu}$-TP3805 tumor volume was $90.6 \% \pm 16.1 \%$ of the ${ }^{18} \mathrm{~F}$ FDG tumor volume. The volume range for the 4 lymph nodes was $28-509 \mathrm{~mm}^{3}$ as determined by ${ }^{18} \mathrm{~F}-\mathrm{FDG}$ and $28-402 \mathrm{~mm}^{3}$ as determined by ${ }^{64} \mathrm{Cu}$-TP3805. The node volume as determined by ${ }^{64} \mathrm{Cu}-\mathrm{TP} 3805$ was $86.2 \% \pm 9.2 \%$ of that found by the ${ }^{18}$ F-FDG scan.

All 6 primary lesions and 4 malignant lymph nodes were unequivocally detected by ${ }^{64} \mathrm{Cu}-\mathrm{TP} 3805 \mathrm{PET} / \mathrm{CT}$ imaging. ${ }^{18} \mathrm{~F}$ FDG PET/CT SUV range was $1.75-12.8$ for the 6 primary lesions and 1.8-11.0 for the malignant lymph nodes. The corresponding ${ }^{64} \mathrm{Cu}-\mathrm{TP} 3805 \mathrm{PUV} / \mathrm{BGV}$ was $1.9-11.8$ for the primary lesions and 2.4-4.9 for the lymph nodes. The ${ }^{64} \mathrm{Cu}-\mathrm{TP} 3805 \mathrm{PET} / \mathrm{CT}$ SUV was $92 \% \pm 26.4 \%$ of the ${ }^{18} \mathrm{~F}-\mathrm{FDG}$ SUV for the primary lesions. The ${ }^{64} \mathrm{Cu}$-TP3805 PET/CT SUV for the malignant lymph nodes was $89.8 \% \pm 27 \%$ of the ${ }^{18}$ F-FDG PET/CT SUV.

The whole-body images revealed liver uptake of ${ }^{64} \mathrm{Cu}-\mathrm{TP} 3805$ (Fig. 1). The value was not quantified. The exact nature of this uptake is unknown. However, our preclinical data had indicated that liver uptake was $25.4 \% \pm 1.74 \%$, of which nearly $60 \%$ of the activity had the same molecular weight as TP3805, and that $7.5 \%$ of the activity was excreted in the feces within $24 \mathrm{~h}$ after injection (26). These preclinical data suggest that most of the liver uptake in patients may be due to intact ${ }^{64} \mathrm{Cu}-\mathrm{TP} 3805$ and that a portion of this may be eliminated through feces.

For the 13 PEM patients, there were 14 primary lesions ( 2 in 1 patient), all of which were unequivocally delineated by ${ }^{64} \mathrm{Cu}-$ TP3805 (Fig. 2). The tumor volume as determined by ${ }^{18} \mathrm{~F}-\mathrm{FDG}$ PEM scans ranged from 141 to $3,818 \mathrm{~mm}^{3}$. The tumor volume range, as calculated from the ${ }^{64} \mathrm{Cu}-\mathrm{TP} 3805$ PEM scans, was 98 to $6,912 \mathrm{~mm}^{3}, 113 \% \pm 37 \%$ of the ${ }^{18} \mathrm{~F}-\mathrm{FDG}$ values.

In PEM imaging, the ratios of PUV to BGV ranged from 2.6 to 11.6 for ${ }^{18} \mathrm{~F}-\mathrm{FDG}$ and from 2.7 to 11.8 for ${ }^{64} \mathrm{Cu}-\mathrm{TP} 3805$. This is $97.7 \% \pm 24.5 \%$ of the ${ }^{18} \mathrm{~F}-\mathrm{FDG}$ values.

Although the sample size is small, these data are important as they establish the utility of the ${ }^{64} \mathrm{Cu}$-TP3805 probe for future clinical applications in patients with BC. Tumor uptake of ${ }^{64} \mathrm{Cu}$-TP3805 as observed in PEM imaging was rapid. The average PUV/BGV ratio calculated for the 13 PEM patients from their 15-min PEM images was $3.1 \pm 2.15$ and remained steady at $3.2 \pm 2.2$ for images obtained $2-3 \mathrm{~h}$ after injection and at $3.3 \pm 2.4$ for images obtained $5 \mathrm{~h}$ after injection (Fig. 3 ). These values were not statistically significantly different $(P \geq 0.5)$.

The tumor volume as determined by ${ }^{18} \mathrm{~F}$-FDG scans most likely represents the total volume of metabolically active malignant cells, and the tumor volume as determined by ${ }^{64} \mathrm{Cu}-\mathrm{TP} 3805$ scans most likely represents the volume of cells that express VPAC1 receptors. The close congruity of tumor volumes $(90.6 \% \pm 16.1 \%$ 


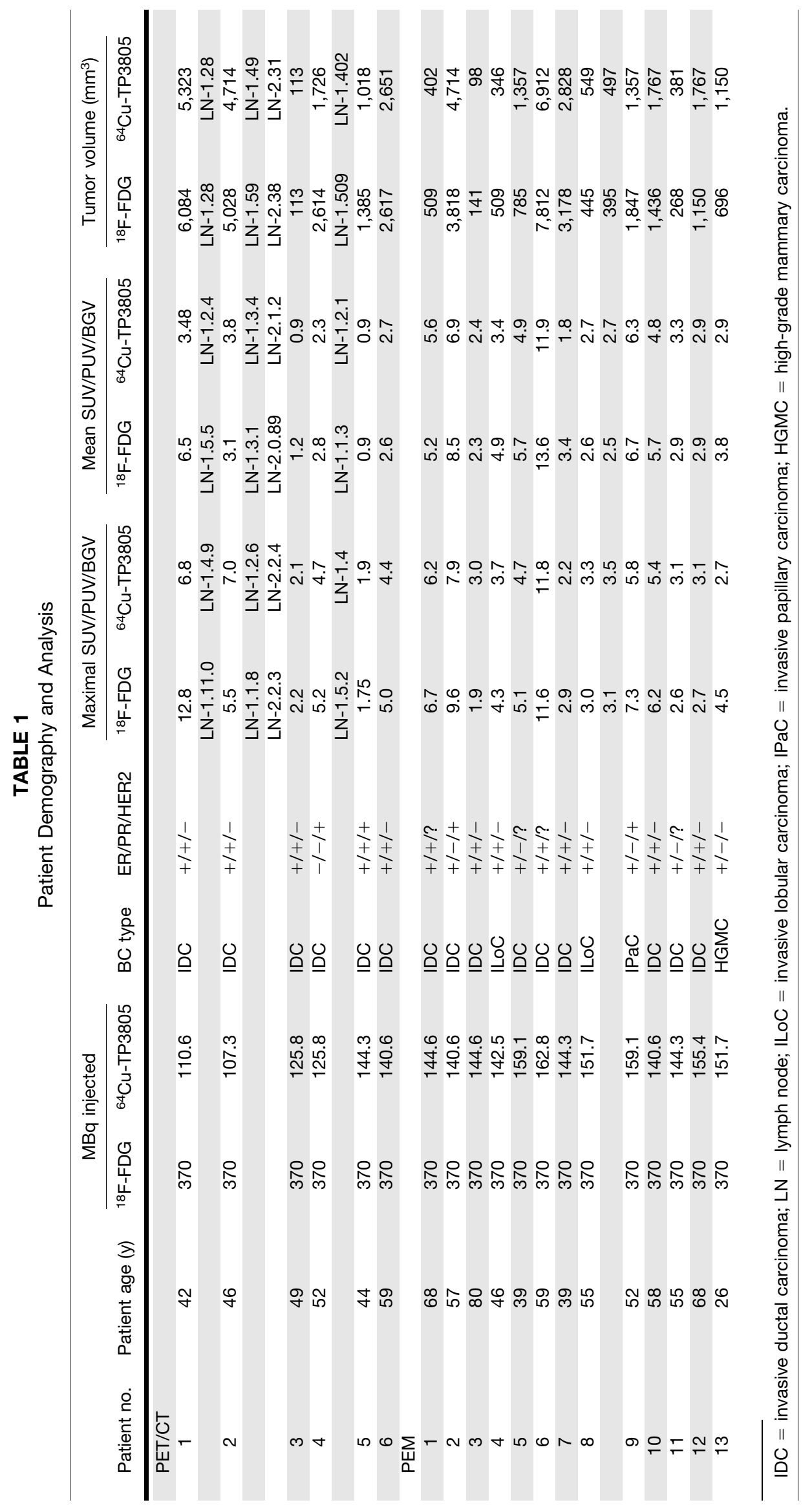




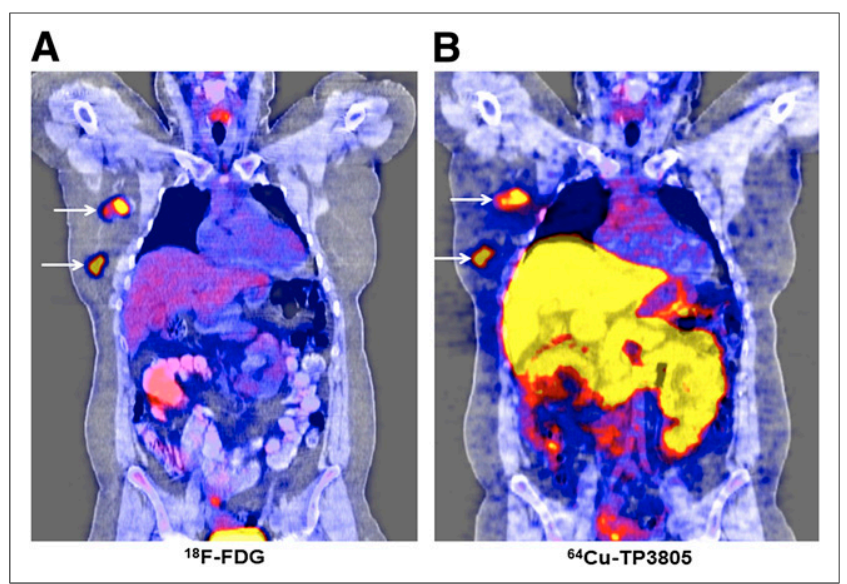

FIGURE 1. A 42-y-old woman with histologically proven invasive ductal carcinoma (ER-positive, PR-positive, $\mathrm{HER}_{2}$-negative) had positive ${ }^{18} \mathrm{~F}-\mathrm{FDG} \mathrm{PET} / \mathrm{CT}$ findings (A) that delineated primary mass in right breast and pair of lymph nodes in axilla. Same lesions were also clearly visible on whole-body ${ }^{64} \mathrm{Cu}-\mathrm{TP} 3805$ PET/CT scan (B) obtained $2 \mathrm{~h}$ after administration of $140.6 \mathrm{MBq}(3.8 \mathrm{mCi})$ of ${ }^{64} \mathrm{Cu}-$ TP3805 ( ${ }^{18} \mathrm{~F}-\mathrm{FDG}$ equivalent, $\left.28,860 \mathrm{kBq}[780 \mu \mathrm{Ci}]\right)$.

and $113 \% \pm 37 \%$, respectively) by the 2 agents indicates that a significantly large number of metabolically active malignant cells express VPAC1 receptors and vice versa.

By design, the ${ }^{64} \mathrm{Cu}-\mathrm{TP} 3805$ received by all 19 patients ranged from 107.3 to $162.8 \mathrm{MBq}$. Given that the positron emission of ${ }^{64} \mathrm{Cu}$ is only $19 \%$, compared with $97 \%$ for ${ }^{18} \mathrm{~F}-\mathrm{FDG}$, the effective ${ }^{64} \mathrm{Cu}$-TP3805 dose ranged from 21 to $33 \mathrm{MBq}$, less than one tenth the dose of ${ }^{18}$ F-FDG. Despite this small amount of tracer, the ${ }^{64} \mathrm{Cu}-\mathrm{TP} 3805$ image quality was excellent, both for PET/CT images (Fig. 1) and for PEM images (Figs. 2 and 3). All malignant lesions ( $n=20)$, including the malignant lymph nodes $(n=4)$, were clearly delineated by ${ }^{64} \mathrm{Cu}-\mathrm{TP} 3805$.

\section{Chemical Toxicity and Radiation Exposure}

${ }^{64} \mathrm{Cu}$ is a rapidly emerging $\beta+$ radionuclide. It is used in humans for PET imaging (American College of Radiology Imaging Network [ACRIN] 6682, phase II trial, 2012) $(28-30) .{ }^{64} \mathrm{Cu}$ has a $t_{1 / 2}(12.8 \mathrm{~h})$ long enough to be dispatched throughout the country but not so long as to deliver an excessive radiation dose to patients after imaging. ${ }^{64} \mathrm{Cu}$ is produced in large quantities on small cyclotrons, and its chemistry is well known. In our PEM studies, 13 patients received $143.19 \mathrm{MBq}(3.87 \mathrm{mCi})( \pm 0.2 \%)$ and an estimated dose of $2.52 \mathrm{mSv}$ to the whole body and 36.5 $\mathrm{mSv}$ to the liver (target organ, eIND 101550). Table 2 shows data for ${ }^{64} \mathrm{Cu}-\mathrm{TP} 3805$ and for other BC imaging agents, such as those used in the ACRIN study and an agent that has been used in humans since $1970,{ }^{67} \mathrm{Ga}$. Data demonstrate that radiation exposure induced by ${ }^{64} \mathrm{Cu}$-TP3805 is less than that induced by the well-established radiotracers and the ACRIN-promoted ${ }^{64} \mathrm{Cu}-$ ATSM (Table 2) (30-34).

Lewis et al. (34) demonstrated that the metal ions in a dose of ${ }^{64} \mathrm{Cu}$ more than 6 times greater than that we propose (same manufacturer) are not toxic. In addition, our data on rabbits receiving a $1,000 \times$ dose (adjusted to body weight) of decayed ${ }^{64} \mathrm{Cu}-\mathrm{TP} 3805$ did not elevate c-AMP, alter blood chemistry, or change liver enzymes. No toxicity was observed in any of the 19 patients who received ${ }^{64} \mathrm{Cu}-\mathrm{TP} 3805$ (eIND 101550).

\section{DISCUSSION}

During the past few decades, advances in imaging BC have contributed extensively to its early detection. Early detection with mammographic screening has been proven to decrease $\mathrm{BC}$ mortality. However, mammography and all other breast imaging modalities produce many suggestive findings, only about $20 \%$ of which will actually be malignant but all of which will require biopsy for diagnosis. In the United States each year, an estimated 1.6 million biopsies are performed. More than 1.3 million of these result in benign pathology, yet they produce patient morbidity and cost billions of dollars to the health care system (2).

A compelling need therefore exists for a biomolecule that will not only detect BC early but also distinguish these malignancies from benign lesions accurately and noninvasively. Such a biomolecule could minimize the need for invasive biopsies and could significantly reduce health care costs.

We hypothesized that VPAC1 oncogene product, which is overexpressed on all $\mathrm{BC}$ cells at the onset of oncogenesis irrespective of their hormonal status, will serve as an excellent biomarker for early and accurate detection of BC. Furthermore, since VPAC1 receptors are not overexpressed on cells of normal breast tissue or benign masses, the probe targeting VPAC1 receptors will image only malignant lesions, not benign masses. We chose to use ${ }^{64} \mathrm{Cu}$ as the probe because of the relatively inferior quality of ${ }^{99 \mathrm{~m}} \mathrm{Tc}-\mathrm{TP} 3654$ (20); the poor resolution of $\gamma$-cameras, which may prevent us from imaging lesions less than $6 \mathrm{~mm}$ in diameter; and the uncertainty about the supply of ${ }^{99 \mathrm{~m}} \mathrm{Tc}$. Furthermore, for ${ }^{64} \mathrm{Cu}$, the resolution of the PEM Solo II (Naviscan) is $2.4 \mathrm{~mm}$ and that of the Clear-PEM (Clear Crystal Collaboration at CERN, Geneva, Switzerland) is $1.3 \mathrm{~mm}$. The resolution of the modern BC imaging camera Dilon 6800 (Dilon Technologies) is $6 \mathrm{~mm}$, and that of the Discovery NM 750b (GE Healthcare) is $3.5 \mathrm{~mm}(20,35)$.

Our PEM image quality is much better with ${ }^{64} \mathrm{Cu}-\mathrm{TP} 3805$ than with ${ }^{99 \mathrm{~m} T c-T P 3654}(20)$. Thus, the ${ }^{64} \mathrm{Cu}$ availability, elimination of CT radiation in PET/CT, high PEM resolution, and better image quality make a compelling case for using ${ }^{64} \mathrm{Cu}$-TP3805 for PEM. Our preliminary data on MMTVneu mice that spontaneously grew

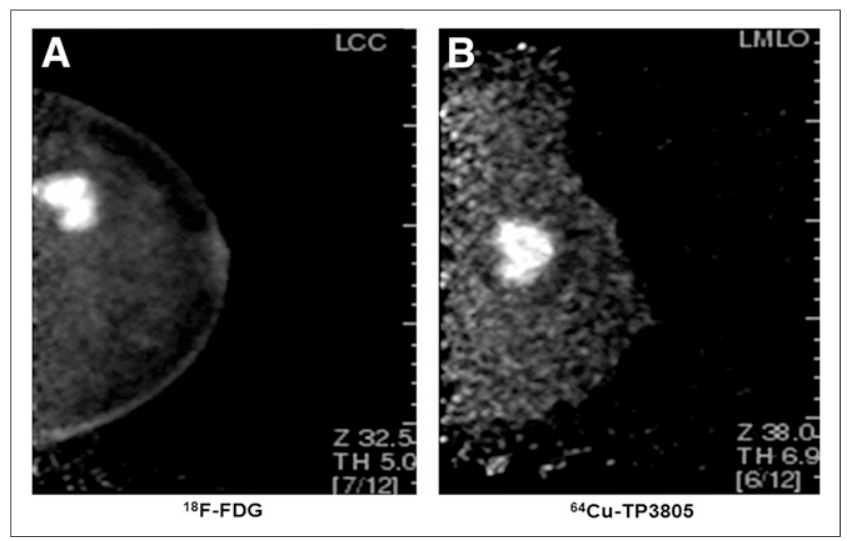

FIGURE 2. ${ }^{18} \mathrm{~F}-\mathrm{FDG}$ PEM scan (A, $370 \mathrm{MBq}[10 \mathrm{mCi}]$ ) of left breast of $39-y$-old woman was obtained $1 \mathrm{~h}$ after injection, and ${ }^{64} \mathrm{Cu}$ TP3805 PEM scan (B, $159.1 \mathrm{MBq}$ [4.3 mCi]; ${ }^{18} \mathrm{~F}-\mathrm{FDG}$ equivalent, $31,820 \mathrm{kBq}[860 \mu \mathrm{Ci}]$ ) was acquired $15 \mathrm{~min}$ after injection. PUV/BGV ratios for lesion (invasive ductal carcinoma, ER-positive, PR-positive, $\mathrm{HER}_{2}$-negative) were 2.9 for ${ }^{18} \mathrm{~F}-\mathrm{FDG}$ and 2.2 (lowest of series) for ${ }^{64} \mathrm{Cu}$-TP3805. 


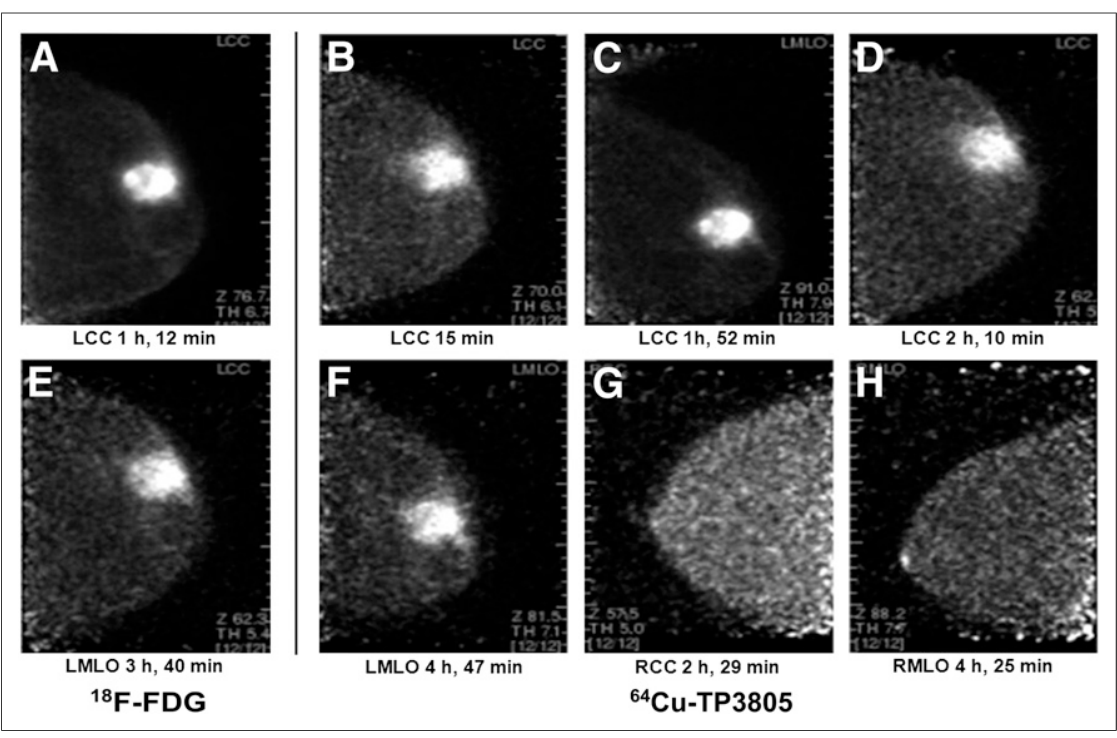

FIGURE 3. One-hour ${ }^{18} \mathrm{~F}-\mathrm{FDG}$ PEM scan (A, $\left.370 \mathrm{MBq}[10 \mathrm{mCi}]\right)$ and longitudinal ${ }^{64} \mathrm{Cu}-$ TP3805 PEM scans (B-F, $162.8 \mathrm{MBq},(4.4 \mathrm{mCi}]) ;{ }^{18} \mathrm{~F}-\mathrm{FDG}$ equivalent, $32,560 \mathrm{kBq}$ [880 $\left.\left.\mu \mathrm{Ci}\right]\right)$ of 59-y-old woman $15 \mathrm{~min}, 1 \mathrm{~h} 52 \mathrm{~min}, 2 \mathrm{~h} 10 \mathrm{~min}, 3 \mathrm{~h} 40 \mathrm{~min}$, and $4 \mathrm{~h} 47 \mathrm{~min}$ after injection. She had invasive ductal carcinoma of left breast (ER-positive, PR-positive, $\mathrm{HER}_{2}$-indeterminate). ${ }^{64} \mathrm{Cu}$-TP3805 PEM images of normal right breast ( $\mathrm{G}$ and $\left.\mathrm{H}\right) 2 \mathrm{~h} 20 \mathrm{~min}$ and $4 \mathrm{~h}$ 25 min after injection are also given. ${ }^{18} \mathrm{~F}-\mathrm{FDG}$ PUV was $11.6 .{ }^{64} \mathrm{Cu}-\mathrm{TP} 3805$ PUV/BGV ratio was 11.9 and remained nearly unchanged for all images (C-F) obtained at various time points after injection. LCC = left craniocaudal; LMLO = left mediolateral oblique; RCC = right craniocaudal; RMLO = right mediolateral oblique.

$\mathrm{BC}$ and mimicked the pathophysiology of human $\mathrm{BC}$ validated our hypothesis in which we had used ${ }^{64} \mathrm{Cu}-\mathrm{TP} 3805$ as the specific probe for PET imaging of primary as well as metastatic BC (26). Furthermore, in this study, ${ }^{64} \mathrm{Cu}-\mathrm{TP} 3805$ did not accumulate in lesions that were shown by histology to be nonmalignant and did not express VPAC1 receptors by reverse transcription polymerase chain reaction (26).

In this present human investigation, designed not as an efficacy study but merely as a feasibility and safety study, ${ }^{64} \mathrm{Cu}-\mathrm{TP} 3805$ imaged all 20 primary malignant tumors in 19 patients ( 1 patient had 2 lesions and the remaining 18 had 1 each). In addition, in whole-body PET/CT imaging, 4 involved sentinel lymph nodes (2 in 1 patient and 1 each in the other 2 patients) were also delineated clearly. Although all lesions were also delineated by ${ }^{18} \mathrm{~F}-\mathrm{FDG}$, in large studies ${ }^{18} \mathrm{~F}-\mathrm{FDG}$ is known to be nonspecific, to miss up to $30 \%$ of $\mathrm{BC}$ lesions, and to not be able to distinguish benign lesions from malignant masses.

In this small patient study, 2 other observations were made that are noteworthy. The first is that the ${ }^{64} \mathrm{Cu}$-TP3805 uptake was rapid, $15 \mathrm{~min}$ after injection. This suggests in principle that, instead of using ${ }^{64} \mathrm{Cu}$ with a $\mathrm{t}_{1 / 2}$ of $12.8 \mathrm{~h}$, we can use generator-produced ${ }^{68} \mathrm{Ga}$ with a $\mathrm{t}_{1 / 2}$ of $68 \mathrm{~min}$. The positron emission of ${ }^{68} \mathrm{Ga}$ is $88 \%$, more than 4 times greater than that of ${ }^{64} \mathrm{Cu}$. This will permit us to administer less than $150 \mathrm{MBq}(\sim 4 \mathrm{mCi})$ of ${ }^{68} \mathrm{Ga}$ without compromising image quality yet significantly reducing radiation burden to the subjects. Images can be obtained 15 min after injection without requiring patient fasting or monitoring of their blood glycemic level.

Second, we observed that the PUV/ $\mathrm{BGV}$ ratios of images obtained in the 15 min after injection did not significantly alter during up to $5 \mathrm{~h}$ of imaging, suggesting that ${ }^{67} \mathrm{Cu}$-TP3805 might be used as a therapeutic agent without alteration in the chemistry of its preparation. ${ }^{67} \mathrm{Cu}$ $\left(\beta-, 100 \% ; t_{1 / 2}, 2.44 d\right)$ is considered a radionuclide of therapeutic importance (36). Although it is not yet available commercially, many facilities in the nation are capable of producing it.

From this small feasibility study, it is also reasonable to point out 2 minor but important observations. One is the tumor volume congruity $\left({ }^{18} \mathrm{~F}-\mathrm{FDG}\right.$ vs. $\left.{ }^{64} \mathrm{Cu}-\mathrm{TP} 3805\right)$, which indicates that most metabolically active malignant cells express VPAC1 receptors and vice versa. The other observation suggests that irrespective of their hormonal status (Table 1) all tumors were unequivocally delineated by ${ }^{64} \mathrm{Cu}-\mathrm{TP} 3805$. These observations need to be substantiated in larger clinical studies.

Because the patient population was small, it is premature to comment on the sensitivity and specificity of ${ }^{64} \mathrm{Cu}-\mathrm{TP} 3805$. Nevertheless, ${ }^{64} \mathrm{Cu}-\mathrm{TP} 3805$ detected all primary lesions $(100 \%)$, delineated all involved sentinel lymph nodes (100\%), and is worthy of further investigation in patients for whom biopsy of suggestive breast lesions is recommended, to evaluate its ability to distinguish benign masses from malignant lesions by PET or PEM imaging (37).

\section{CONCLUSION}

There is a compelling need for a biomolecule that will distinguish malignant from benign lesions noninvasively. ${ }^{64} \mathrm{Cu}-$ TP3805 promises to be such an agent. In this feasibility study,

TABLE 2

Comparative Radiation Dosimetry

\begin{tabular}{|c|c|c|c|}
\hline Procedure & Effective dose (mSv) & Liver dose (mSv) & Reference \\
\hline${ }^{64} \mathrm{Cu}-\mathrm{TP} 3805$ (148 MBq [4 mCi]) & 2.5 & 36.5 & Gingold E, elND 101550 \\
\hline${ }^{18} \mathrm{~F}-\mathrm{FDG}$ PET/CT $\left({ }^{18} \mathrm{~F}, 370 \mathrm{MBq}[10 \mathrm{mCi}]\right)$ & 31.9 & 5.8 & 31 \\
\hline 99mTc-sestamibi $(1,110 \mathrm{MBq}[30 \mathrm{mCi}])$ & 9.4 & 6.0 & 32 \\
\hline${ }^{18} \mathrm{~F}-\mathrm{FDG}$ PET/PEM without CT $\left({ }^{18} \mathrm{~F}, 370 \mathrm{MBq}[10 \mathrm{mCi}]\right)$ & 7.8 & 5.8 & 32 \\
\hline${ }^{67} \mathrm{Ga}$-citrate (370 MBq [10 mCi]) & 39 & 69 & 33 \\
\hline${ }^{64} \mathrm{Cu}-\mathrm{ATSM}$ (925 MBq [25 mCi]) & 33.3 & 361 & 34 \\
\hline
\end{tabular}


${ }^{64} \mathrm{Cu}$-TP3805, which targets VPAC1 oncogene receptors, unequivocally detected all malignant breast lesions by PET/CT and PEM and delineated all involved lymph nodes. These results warrant further studies in patients to validate the hypothesis that ${ }^{64} \mathrm{Cu}-$ TP3805 will help reduce the number of unnecessary biopsies, minimize patient anxiety, and reduce health care cost.

\section{DISCLOSURE}

The costs of publication of this article were defrayed in part by the payment of page charges. Therefore, and solely to indicate this fact, this article is hereby marked "advertisement" in accordance with 18 USC section 1734 . This study was supported by NIH CA 109231 and in part by NuView Inc. The support of Naviscan, Inc., for the use of Solo I PEM is gratefully acknowledged. Mathew Thakur is a consultant to NuView. No other potential conflict of interest relevant to this article was reported.

\section{ACKNOWLEDGMENTS}

We thank Gordon Schwartz, Sun Yong Lee, Anne Rosenberg, Eric Gingold, Constantine Daskalakis, and Colleen Dascenzo of Thomas Jefferson University. The technical contribution of Judith Carr, Jessica Shell, and Brian Schulli is gratefully recognized.

\section{REFERENCES}

1. DeSantis C, Siegel R, Bandi P, et al. Breast cancer statistics, 2011. CA Cancer J Clin. 2011;61:409-418.

2. Elter M, Schulz-Wendtland R, Wittenberg T. The prediction of breast cancer biopsy outcomes using two CAD approaches that both emphasize an intelligible decision process. Med Phys. 2007;34:4164-4172.

3. Uematsu T, Sano M, Homma K. False-positive helical CT findings of multifocal and multicentric breast cancer: is attenuation of tumor useful for diagnosing enhanced lesions? Breast Cancer. 2002;9:62-68.

4. Berg WA, Gutierrez L, NessAiver MS, et al. Diagnostic accuracy of mammography, clinical examination, US, and MR imaging in preoperative assessment of breast cancer. Radiology. 2004;233:830-849.

5. Ruibal A, Maldinado A, Sanchez Salmon A, et al. ${ }^{18}$ FDG-PET in patients with situ breast carcinomas: a cause of false negative results. Med Clin (Barc). 2008;130:332-333.

6. Tse GM, Yang W. Sonographic, mammographic, and histopathologic correlation of symptomatic ductal carcinoma in situ. AJR. 2004;182:101-110.

7. Elmore JG, Armstrong K, Lehman CD, et al. Screening for breast cancer. JAMA. 2005;293:1245-1256.

8. Ghai S, Muradali D, Bukhanov K, et al. Nonehancing breast malignancies on MRI: sonographic and pathologic correlation. AJR. 2005;185:481-487.

9. Chagpar AB, Middleton LP, Sahin AA, et al. Accuracy of physical examination, ultrasonography, and mammography in predicting residual pathologic tumor size in patients treated with neoadjuvant chemotherapy. Ann Surg. 2006;243:257264.

10. Xu HB, Li L, Xu Q. Tc-99m sestamibi scintimammography for the diagnosis of breast cancer: meta-analysis and meta-regression. Nucl Med Commun. 2011;32: 980-988.

11. Xue DQ, Qian C, Yang L, Wang XF. Risk factors for surgical site infections after breast surgery: a systematic review and meta-analysis. Eur J Surg Oncol. 2012; 38:375-381.

12. Printz C. Unnecessary breast cancer biopsies still performed. Cancer. 2010;116: 1619.

13. Reubi JC, Laderach U, Waser B, et al. Vasoactive intestinal peptide/pituitary adenylate cyclase-activating peptide receptor subtypes in human tumors and their tissues of origin. Cancer Res. 2000;60:3105-3112.
14. Zia H, Hida T, Jakowlew $\mathrm{S}$, et al. Breast cancer growth is inhibited by vasoactive intestinal peptide, (VIP) hybrid, a synthetic VIP receptor antagonist. Cancer Res. 1996;56:3486-3489.

15. Leyton J, Gozes Y, Pisegna J, et al. PACAP(6-38) is a PACAP receptor antagonist for breast cancer cells. Breast Cancer Res Treat. 1999;56:177-186.

16. Moody TW, Gozes I. Vasoactive intestinal peptide receptors: a molecular target in breast and lung cancer. Curr Pharm Des. 2007;13:1099-1104.

17. Valdehita A, Bajo AM, Fernández-Martínez AB, et al. Nuclear localization of vasoactive intestinal peptide (VIP) receptors in human breast cancer. Peptides. 2010;31:2035-2045.

18. Valdehita A, Carmena MJ, Bajo AM, Prieto JC. RNA interference-directed silencing of VPAC1 receptor inhibits VIP effects on both EGFR and HER2 transactivation and VEGF secretion in human breast cancer cells. Mol Cell Endocrinol. 2012;348:241-246.

19. Chakder S, Rattan S. The entire vasoactive intestinal polypeptide molecule is required for the activation of the vasoactive intestinal polypeptide receptor: functional and binding studies. J Pharmacol Exp Ther. 1993;266:392-399.

20. Thakur ML, Marcus CS, Saeed S, et al. $99 \mathrm{~m}$ Tc-labeled vasoactive intestinal peptide analog for rapid localization of tumors in humans. J Nucl Med. 2000;41:107-110.

21. Pallela VR, Thakur ML, Chakder S, et al. ${ }^{99 \mathrm{~m}} \mathrm{Tc}$-labeled vasoactive intestinal peptide receptor agonist: functional studies. J Nucl Med. 1999;40:352-360.

22. Kolan HR, Pallela V, Thakur ML. Tc-99m labeled vasoactive intestinal peptide, (VIP): preparation and preliminary evaluation. J Labelled Comp Radiopharm. 1997;40:455-457.

23. Thakur ML, Aruva M, Gariepy J, et al. Imaging oncogene overexpression using

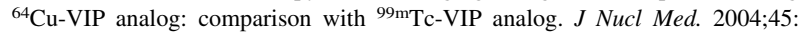
1381-1389.

24. Zhang K, Aruva M, Shanthly N, et al. Vasoactive intestinal peptide (VIP) and pituitary adenylate cyclase activating peptide (PACAP) receptor specific peptide analogues for PET imaging of breast cancer: in vitro/in vivo evaluation. Regul Pept. 2007;144:91-100.

25. Thakur ML. Genomic biomarkers for molecular imaging: predicting the future. Semin Nucl Med. 2009;39:236-246.

26. Thakur ML, Devadhas D, Zhang K, et al. Imaging spontaneous MMTVneu transgenic murine mammary tumors: targeting metabolic activity versus genetic products. J Nucl Med. 2010;51:106-111.

27. Zhang K, Aruva MR, Shanthly N, et al. PET imaging of VPAC1 expression in experimental and spontaneous prostate cancer. J Nucl Med. 2008;49:112-121.

28. Anderson CJ, Dehdashti F, Cutler PD, et al. ${ }^{64} \mathrm{Cu}$-TETA-octreotide as a PET imaging agent for patients with neuroendocrine tumors. J Nucl Med. 2001;42: 213-221.

29. Lewis J, Laforest R, Buettner T, et al. Copper-64-diacetyl-bis(N4-methylthiosemicarbazone): an agent for radiotherapy. Proc Natl Acad Sci USA. 2001;98: 1206-1211.

30. Pfeifer A, Knigge U, Mortensen J, et al. Clinical PET of neuroendocrine tumors using ${ }^{64} \mathrm{Cu}$-DOTATATE: first-in-humans study. J Nucl Med. 2012;53:1207-1215.

31. Huang B, Law MW, Khong PL. Whole-body PET/CT scanning: estimation of radiation dose and cancer risk. Radiology. 2009;251:166-174.

32. Hendrick RE. Radiation doses and cancer risks from breast imaging studies. Radiology. 2010;257:246-253.

33. MIRD-dose estimate report no. 2: summary of current radiation dose estimates to humans from ${ }^{66} \mathrm{Ga}-,{ }^{67} \mathrm{Ga}-,{ }^{68} \mathrm{Ga}$-, and ${ }^{72} \mathrm{Ga}$-citrate. J Nucl Med. 1973;14:755756.

34. Lewis JS, Laforest R, Dehdashti F, et al. An imaging comparison of ${ }^{64} \mathrm{Cu}$ ATSM and ${ }^{60} \mathrm{Cu}$-ATSM in cancer of the uterine cervix. J Nucl Med. 2008; 49:1177-1182.

35. Moadel RM. Breast cancer imaging devices. Semin Nucl Med. 2011;41:229-241.

36. Knogler K, Grünberg J, Zimmermann K, et al. Copper-67 radioimmunotherapy and growth inhibition by anti-L1-cell adhesion molecule monoclonal antibodies in a therapy model of ovarian cancer metastasis. Clin Cancer Res. 2007;13: 603-611.

37. Berg WA, Weinberg IN, Narayanan D, et al. High-resolution fluorodeoxyglucose positron emission tomography with compression ("positron emission mammography") is highly accurate in depicting primary breast cancer. Breast J. 2006; 12:309-323. 